\title{
Regional Zoning of Territories According to the Level of Primary Diamond Sources' Diamondiferousness
}

Zintchouk, N.N., Zuev, V.M., Mitioukhine, S.I.

YaGEER\&D CNIGRI, ALROSA Co. Ltd. Chernyshevsky Sh. 7, Mirny, 678170, Sakha (Yakutia), Russia.

Introduction

Analysis of literary data, devoted to the problems of genesis of diamonds and diamondiferous rocks, shows that the term "diamondiferousness" is interpreted rather indefinitely. First of all there is no clearly determined border between geologicmineralogical and geologic-industrial aspects of this term. As a consequence natural targets under general name "diamondiferous bodies" representing genetically heterogeneous aggregate are united in one group. The reason is in the fact that the structure and properties of diamond raw material in primary sources are still investigated to a small degree.

Heterogeneity of natural diamondiferous targets of industrial type.

It is known that a relative number of magmatic bodies, composed by kimberlites and associated with them rocks and containing diamonds, is rather large. However, in the course of diamond mining history not more than 100 targets were involved in exploitation. In Fig. 1 there is the data about the cost of diamonds in a ton of ore in primary deposits of the World, which are the main economic characteristics of targets. A large scale of changeability (more than 10 times) of this parameter is noted. These data also indicate that there is no common criterion which could determine minimumindustrial level of diamondiferousness.

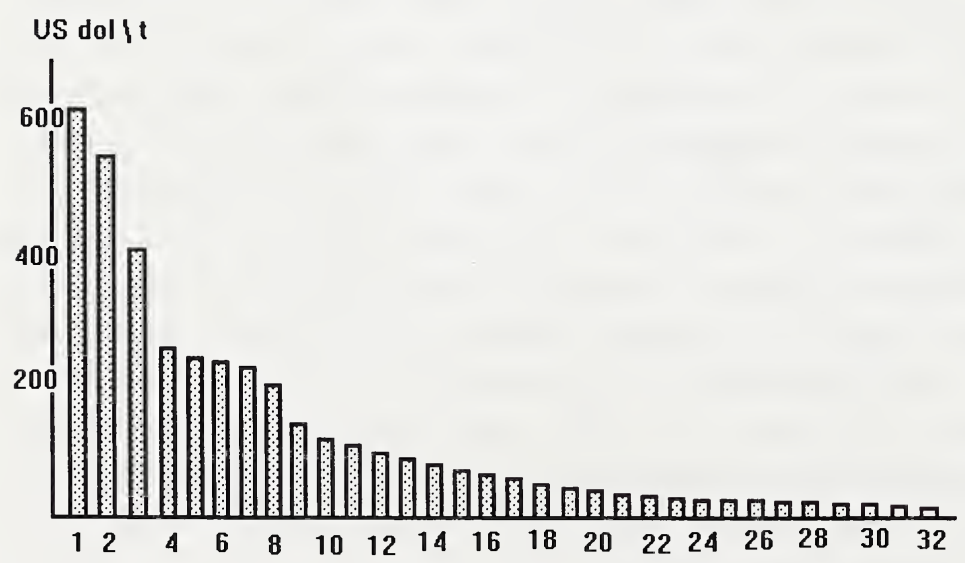


Fig. 1. Classification of diamondiferous bodies according to the cost of diamonds in a ton of ore.

1-3, 5, 7, 14, 16, 20 (pipes of Yakutian subprovince); 4-A418, 6-A154, 10-Panda, 12Koala, 13-Misery, 18-Sable, 22-Fox (the pipes of subprovince Slave); 8-Kimberley, 9Jwaneng,

17-De Beers, 21-Finsch, 23-Orapa, 24-Mwadui, 25-Bultfontein, 26-Catoca, 27-Wesselton, 29-Camute, 30-Koffifontein, 31-Jagersfontein, 32-Premier (the pipes of African kimberlite province); 15-Shengly (North-Chinese subprovince); 19-Argyle (West-Australian subprovince); 28- Majhgavan (Indian kimberlite province)

Adoption of a decision about involving a target into exploitation is determined not by geologic-mineralogical characteristics of the target, but by local geographic-economical conditions. It is clear that investigations of geologists-analysts, who carry out comparative analysis of geological structure of diamondiferous regions, internal structure of kimberlite clusters or material composition of separate bodies, may lead to wrong conclusions if they make use of geologic-industrial classification of targets.

Geologic-mineralogical characteristics of diamondiferous targets.

The list of geologic-mineralogical characteristics of diamondiferous targets includes general content of diamonds (weight and quantity of crystals), correlation of granulometric classes, correlation of crystallomorphological forms, degree of natural defectiveness (density of non-plastic deformations, availability of regenerational and corrosive sculptural forms, saturation of crystals by inclusions). Multiplicity and variations in the meanings of the above stated parameters are determined by specific features of natural processes in the course of the whole evolution of diamonds. The main stages are: origination, growth, crystallomorphological transformation and dissolution.

Classification of diamondiferous bodies according to geologic-mineralogical parameters. By interrelation of geologic-mineralogical parameters all the totality of the most investigated targets, which are indicated in Fig. 1, may be subdivided into three groups: A, B, C. Group A is formed by pipes-leaders from kimberlite fields of Yakutian province (Russia) and the Slave province (Canada) (preliminary data). It is established $(1,2)$ that among the diamonds there prevail (more than $70 \%$ of crystals) octahedral, rhombododecahedral and transitive crystallomorphological varieties, the rest are represented by rounded (curve-faceted) diamonds, cubic diamonds and shapeless fragments. Regardless of the form practically all the diamonds (95\%) refer to the so called first genetic variety (3). It is also found (1) that the increase of the curve-faceted diamonds share up to $18-20 \%$ corresponds to sharp decrease of general weight content to the level of poor diamondiferousness. Furthermore, distribution of diamonds by classes of large size in kimberlite pipes of group A is also regular. It is described by the chart in Fig. 2. Group B is formed by pipes-leaders of South-African kimberlite province. The same as for group A there prevail diamonds of the first genetic variety, however correlation of diamonds of different morphological shapes shifts to the variant of combinational shapes of octahedronrhombododecahedron with increase of the share of curve-faceted (shapes of dissolution) varieties. Investigation of composition of fluid inclusions and correlations $\mathrm{H}: \mathrm{O}: \mathrm{C}: \mathrm{N}$ (3) make it possible 
to suggest that group B targets diamonds crystallized and developed in a more oxidized environment than diamonds of group A. These conditions reflected in relative decrease of general weight content of diamonds and distribution of crystals by classes of large size. Group B is formed by pipes-leaders of South-African kimberlite province. The same as for group A there prevail diamonds of the first genetic variety,

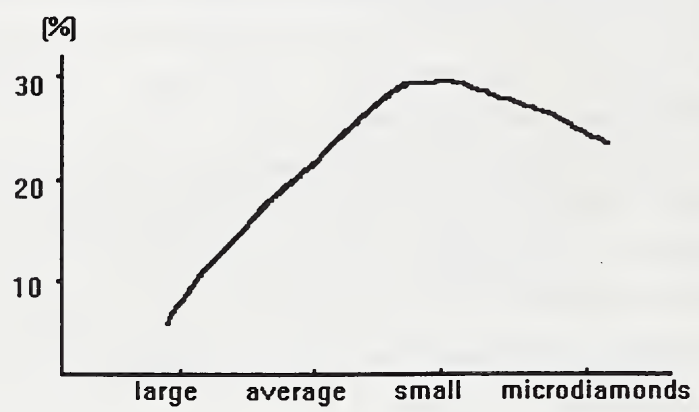

Fig. 2. Distribution of diamonds (in weight) of various granulometric classes in diamondiferous bodies of group A

however correlation of diamonds of different morphological shapes shifts to the variant of combinational shapes of octahedron-rhombododecahedron with increase of the share of curvefaceted (shapes of dissolution) varieties. Investigation of composition of fluid inclusions and correlations $\mathrm{H}: \mathrm{O}: \mathrm{C}: \mathrm{N}(3)$ make it possible to suggest that group B targets diamonds crystallized and developed in a more oxidized environment than diamonds of group A. These conditions reflected in relative decrease of general weight content of diamonds and distribution of crystals by classes of large size.

Group C comprises a large number of diamondiferous bodies of kimberlite and lamproite nature of African, East-European, Chinese and Australian platforms. Their main feature is insignificant presense of diamonds of the first genetic variety at broad distribution of diamonds of other genetic groups. Those are yellow and orange crystalls of cubic shape of growth (variety II), semitransparent crystals of cubic shape, complicated by the development of other facets (variety III), crystals in coatings (coated diamonds) (variety IV) and others, corresponding to varieties V-XI.

Regularities between qualitative and quantitative parameters of diamond raw material in geological targets make it possible to determine the notion "diamondiferousness" from geologic-genetic positions and avoid possible mistakes when using this notion from geologic-industrial point of view. In particular it is important when carrying out investigations, the aim of which is to reveal general features of geological structure and development of diamondiferous territories.

\section{References}

Koptil, V.I., 1994, Typomorphism of diamonds of the north-east of the Siberian platform in connection with the problem of forecasting and prospecting of diamond deposits. Novosibirsk. Kharkiv, A.D., Kvasnitsa, V.N., Safronov, A.F., Zintchouk, N.N. 1989, Typomorphism of diamond and its indicator-minerals from kimberlites. Kiev.

Orlov, Y.L., 1963, Moscow. 